\title{
O lugar da terapêutica na psicanálise: Freud e Lacan*
}

The place of therapeutical in psychoanalysis: Freud and Lacan

El lugar del terapéutico en psicoanálisis: Freud y Lacan

Ednei Soares ${ }^{* *}$

psicanálise produz efeitos terapêuticos. Mais do que verificar os
efeitos terapêuticos de tratamentos orientados pela psicanálise
(uma ideia embrionária do pré-projeto da pesquisa em questão), o caminho que este trabalho tomou foi, circunscrevendo na própria obra de Freud e de Lacan, a discussão em torno da produção desses efeitos no tratamento psicanalítico e o lugar que eles aí ocupam. Trata-se de circunscrever um problema que vai se delineando no decorrer da própria pesquisa.

O modo como essa discussão se dá em cada um desses autores e o lugar que o terapêutico ocupa na consideração de ambos não é precisamente o mesmo. Embora o projeto lacaniano da releitura de Freud seja bastante cauteloso em não se contrapor ou se chocar com as expectativas freudianas, não se trata de programas terapêuticos ou de aspiraçôes clínicas idênticas entre Freud e Lacan. O percurso dessa dissertação acabou por encontrar meios de investigar a questão do terapêutico na psicanálise em Freud e Lacan, de modo que algumas dessas diferenças pudessem ser iluminadas, considerando os limites de um trabalho dissertativo.

A organização deste trabalho dissertativo apresentou, primeiramente, pesquisas cujos dados afirmam a eficácia terapêtica produzida em tratamentos psicanalíticos. Foi possível examinar como tais verificaçôes remontam desde o tempo de Freud até nossos dias. Em face de tais dados, deu-se consequência à noção de efeito e de causa na teoria psicanalítica, tal como articulada por Lacan. Nesse sentido, a noção de desejo se fez ponto de investigação central em sua abordagem teórico-clínica. A

\footnotetext{
Resumo da dissertação apresentada ao Programa de Pós-Graduação Stricto Sensu em Psicologia da Pontifícia Universidade Católica de Minas Gerais, sob a orientação de Cristina Moreira Marcos e com a participação, no exame de qualificação e na defesa, dos professores Antônio Márcio Ribeiro Teixeira (UFMG) e Christian Ingo Lenz Dunker (USP).

* Mestre em Psicologia pela PUC-Minas, psicanalista. Rua Equador, n¹90/201, São Pedro. Belo Horizonte-MG. E-mail: soares.ednei@yahoo.com.br.
} 
articulação lacaniana permitiu interrogar a causa em jogo na produção desses efeitos. Consequentemente, consagrou-se um exame especial à noção de desejo do analista, suas relações com a terapêutica e sua herança encontrada no então denominado por Lacan desejo de Freud.

Em decorrência dessa herança, a pesquisa empreendeu um exame sobre como Freud equacionou seu próprio desejo diante de sua formação médica e de como o jovem vienense foi da terapêutica à psicanálise. A aventura do jovem Freud conviveu com personagens importantes da terapêutica médica, com seu interesse por quadros patológicos enigmáticos, com ideais de pesquisa e de cura, os quais tiveram de enfrentar limites e declínios em vista das surpresas advindas de seu desejo e seus achados. Como resultado, vemos delinear a própria invenção da psicanálise, suas especificidades, suas recomendações técnicas e os resíduos dos efeitos terapêuticos por ela causados. Os restos em questão também foram centrais para pensarmos nas soluções lacanianas para abordar o sintoma e seu destino no tratamento.

No período "Pré-psicanalítico", investigado nesse trabalho, ou mesmo no decorrer da descoberta do inconsciente, Freud conservou não só um entusiasmo pelo efeito terapêutico como também a importou alguns conceitos derivados de sua formação médica. Com o intuito de caracterizar seu novo método, vemos gravitar em torno da obra freudiana termos do alemão que guardam claramente a herança do universo da clínica medica, tais como Therapie, Genesung, Heilung, Behandlung, Sorge e Kur. ${ }^{1}$

Entretanto, mesmo conservando nomeações de outros campos, a psicanálise, enquanto aquela que ganharia status de "corte epistemológico" (Bachelard, 1938/1996), levou Freud a avançar na criação de novos conceitos no âmbito de sua clínica. Tais conceitos ganhariam maior precisão e ajustar-se-iam pouco a pouco em seu sistema teórico (Althusser, 1973). Em resultado à produção de conceitos próprios à clínica psicanalítica, vê-se em Freud um paradoxo: a certeza sobre a eficácia dos efeitos terapêuticos no tratamento conviverá com contrapontos, ora advindos de suas descobertas clínicas e teóricas como resistência, compulsão à repetição e pulsão de morte (para situar algumas), ora das recomendações sobre furor sanandi (Freud, 1912/1976) e avaliações em torno do terapêutico, como manifesta o tom franco de seu

\footnotetext{
Vale lembrar que cada um desses termos recebem, na língua alemã, significados específicos, sobretudo no âmbito da saúde e da clínica médica. Contudo, lamentavelmente, a riqueza de seus significados se perdeu na tradução para o português das tradicionais Ediçōes Standard Brasileiras.
} 
Análise terminável e interminável (Freud, 1937/1976), sobre os limites da eficácia terapêutica da psicanálise.

Situar a psicanálise como um método terapêutico, como o fez Freud (1932/1976), não define o engajamento de Lacan. O psicanalista francês afirma: "A psicanálise não é uma terapêutica como as outras" (Lacan, 1958a/1998, p. 236). Se Freud apresentou, em seu primeiro momento, um entusiasmo, convertido, posteriormente, em cautela sobre o terapêutico na psicanálise, sobretudo para distingui-la como prática singular, não encontramos em Lacan simpatia ou entusiasmo algum, por assim dizer, pela temática da terapêutica. O que não significa que Lacan desconsidera a presença dos efeitos terapêuticos e as relações entre terapêutico e a psicanálise. Nessa vertente, muito embora Lacan (1936/1998, p. 85) considere que a experiência analítica "constitui o elemento da [...] terapêutica”. Para abordá-lo, segundo Lacan, é necessário senso teórico para definir o que essa terapêutica produz (LACAN, 1936/1998). Lacan, portanto, reivindicará a particularidade da psicanálise "por trás da égide terapêutica" (LACAN, 1957/1998, p. 517). Revigorando a questão de Freud, Lacan (1964/1998, p. 867) pergunta: "Qual pode ser o desejo do analista? Qual pode ser o tratamento a que ele se dedica?".

$\mathrm{Na}$ ambição de formular uma ética que integrasse as conquistas freudianas, seria necessário, segundo Lacan, colocar em seu vértice a questão do desejo do analista (LACAN, 1958c/1998, p. 621). Para isso, Lacan estabeleceu um princípio: "É o desejo do analista que, em última instância, opera na psicanálise" (LACAN, 1964/1998, p. 868). Mas o que causaria esse desejo? Ou, o que o definiria? Segundo Lacan (195960/1997, p. 267), o que o designaria de modo decisivo seria "um não desejo de curar".

Proposições lacanianas como essa envolvem um teor negativo estranho ao discurso universitário (por que não dizer, estranho à ambição de clareza dos trabalhos acadêmicos). Contudo, tal negatividade demonstra como os modos de subjetivação propostos na clínica lacaniana tentam reconhecer a negação ontológica revelada entre sujeito e objeto. Esse tipo de elaboração permite acolher o elemento incalculável presente numa análise, o qual não pode ser fixado em nenhuma cláusula contratual terapêutica, mas que, ao contrário, a excede. Não há, portanto, como saber, a priori, o resultado (terapêutico ou não) de um tratamento analítico. A negatividade em jogo nessas elaborações, respondem, finalmente, à exigência do objeto próprio com que a psicanálise lida em sua práxis (tratamento e teoria). 


\section{Referências}

Althusser, L. (1973). Resposta a John Lewis. Lisboa: Estampa; Martins Fontes.

Bachelard, G. (1996). A Formação do espirito científico. Rio de Janeiro: Contraponto. (Trabalho original publicado em 1938).

Freud, Sigmund. (1976). Análise terminável e interminável. In: Edição standard brasileira das obras psicológicas completas de Sigmund Freud. (Christiano Monteiro Oiticica, trad., Vol. 23, p. 239-287). Rio de Janeiro: Imago. (Texto original publicado em 1937).

Freud, Sigmund. (1976). Histeria. In: Edição standard brasileira das obras psicológicas completas de Sigmund Freud. (Christiano Monteiro Oiticica, trad., Vol. 1, p. 65-83). Rio de Janeiro: Imago. (Texto original publicado em 1888).

Freud, Sigmund. (1976). Recomendaçōes aos médicos que exercem a psicanálise. In: Edição standard brasileira das obras psicológicas completas de Sigmund Freud. (Christiano Monteiro Oiticica, trad., Vol. 12. p. 145-159). Rio de Janeiro: Imago. (Texto original publicado em 1912).

Freud, Sigmund. (1977). Troisième leçon. In: Cinq leçons sur la psychanalyse. (pp. 44-45). Paris: Payot. (Texto original publicado em 1909).

Lacan, Jacques. (1998). Para-além do princípio de realidade. In: Escritos. (pp. 83-84). Rio de Janeiro: Jorge Zahar. (Texto original publicado em 1936).

Lacan, Jacques. (1998). A coisa freudiana. In: LACAN, Jacques. Escritos. ( $p$ p. 402-437). Rio de Janeiro: Jorge Zahar. (Texto original publicado em 1956).

Lacan, J. (1998). A direção do tratamento e os princípios de seu poder. In: Escritos. (pp. 591-652). Rio de Janeiro: Jorge Zahar. (Texto original publicado em 1958c).

Lacan, Jacques. (1998). A ciência e a verdade. In: Escritos. (pp. 869-892). Rio de Janeiro: Jorge Zahar, 1998. (Texto original publicado em 1966).

Lacan, Jacques. (1998). A instância da letra no inconsciente ou a razão desde Freud. In: Escritos. (pp. 496-533). Rio de Janeiro: Jorge Zahar. (Texto original publicado em 1957a).

Lacan, J. (1998). A significação do falo. In: Escritos. (pp. 692-703). Rio de Janeiro: Jorge Zahar. (Texto original publicado em 1958a). 
Lacan, Jacques. (2003). Ato psicanalítico: resumo sobre o seminário de 19671968. In: Outros escritos. (p. 378). Rio de Janeiro: Jorge Zahar.

Lacan, Jacques. (1998). Do Trieb de Freud e do desejo do psicanalista. In: Escritos. (pp. 865868). Rio de Janeiro: Jorge Zahar. (Texto original publicado em 1964).

Lacan, Jacques. (1965-1966). Le séminaire, livre 13: L’objet de la psychanalyse. Paris: inédito.

Lacan, Jacques. (1966-1967). Le séminaire, livre 14: la logique du fantasme. Paris: inédito.

Lacan, Jacques. (1997). O seminário, livro 7: a ética da psicanálise (19591960). Rio de Janeiro: Jorge Zahar. (Texto original publicado em 1986).

Lacan, Jacques. (1992). O seminário, livro 17: o avesso da psicanálise (19691970). Rio de Janeiro: Jorge Zahar. (Texto original publicado em 1991).

Lacan, Jaques. (1985). Seminário 20: mais, ainda. (p. 201). Rio de Janeiro: Jorge Zahar, 1985. (Texto original publicado em 1973).

Lacan, Jacques. (1998). Subversão do sujeito e dialética do desejo no inconsciente freudiano. In: Escritos. (pp. 807-842). Rio de Janeiro: Jorge Zahar, 1998. (Texto original publicado em 1960).

Lacan, Jacques. (2010). Transferência para Saint Denis? Lacan a favor de Vincennes. São Paulo. Correio, 65, 31-32. (Texto original publicado em 1978).

Lacan, Jacques. (2003). Televisão. In: Outros escritos. (pp. 508-543). Rio de Janeiro: Jorge Zahar. (Texto original publicado em 1973).

Lacan, Jacques. (1998). Variantes do tratamento padrão. In: Escritos. (pp. 325-364). Rio de Janeiro: Jorge Zahar. (Texto original publicado em 1958b).

Lévi-Strauss, Claude. (1973). A eficácia simbólica. In: Antropologia estrutural. (pp. 215-236). Rio de Janeiro: Tempo Brasileiro. (Texto original publicado em 1949).

Mandil, Ram. (2003). Os efeitos da letra: Lacan leitor de Joyce. Rio de Janeiro: Contra Capa.

Soler, Colette. (1998). Sintomas. Santafé de Bogotá: Asociación del Campo Freudiano de Colombia, Bogotá. 